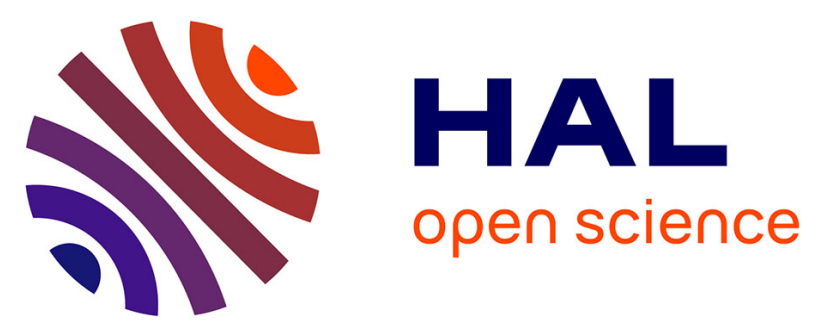

\title{
Preparation and characterization of continuous fly ash derived glass fibers with improved tensile strength
}

Qian Ma, Linfeng Ding, Qingwei Wang, Ye Yu, Lida Luo, Hong Li

\section{To cite this version:}

Qian Ma, Linfeng Ding, Qingwei Wang, Ye Yu, Lida Luo, et al.. Preparation and characterization of continuous fly ash derived glass fibers with improved tensile strength. Materials Letters, 2018, 231, pp.119 - 121. 10.1016/j.matlet.2018.08.032 . hal-01858067

\section{HAL Id: hal-01858067 https://hal.science/hal-01858067}

Submitted on 19 Aug 2018

HAL is a multi-disciplinary open access archive for the deposit and dissemination of scientific research documents, whether they are published or not. The documents may come from teaching and research institutions in France or abroad, or from public or private research centers.
L'archive ouverte pluridisciplinaire HAL, est destinée au dépôt et à la diffusion de documents scientifiques de niveau recherche, publiés ou non, émanant des établissements d'enseignement et de recherche français ou étrangers, des laboratoires publics ou privés.

\section{(ㅇ)(1) $\$$}

Distributed under a Creative Commons Attribution - NonCommercial - NoDerivatives| 4.0 


\title{
Preparation and characterization of continuous fly ash derived glass fibers with improved tensile strength
}

\author{
Qian $\mathrm{Ma}^{1}$, Linfeng Ding ${ }^{2 *}$, Qingwei Wang ${ }^{1 *}, \mathrm{Ye} \mathrm{Yu}^{1}$, Lida Luo ${ }^{1}$, Hong $\mathrm{Li}^{3}$ \\ ${ }^{1}$ State Key Laboratories for Modification of Chemical Fiber and Polymer Materials, Donghua University, \\ Shanghai 201620, People's Republic of China \\ ${ }^{2}$ Institute of Geosciences, Johannes Gutenberg University, 55128 Mainz, Germany \\ ${ }^{3}$ Fiber Glass, Glass Business and Discovery Center, PPG Industries, Inc., Pittsburgh, Pennsylvania \\ *Corresponding author: dingli@uni-mainz.de, wqwq888@dhu.edu.cn
}

\begin{abstract}
The coal-based energy production in China generates more than 600 million tons of coal fly ash (CFA) each year, which drives us searching for new methods for recycling CFA. In this work, continuous glass fibers with a range of CFA ( $25 \%$ - $45 \%)$ were successfully prepared without showing any sign of fiber crystallization. The measured fiber tensile strength was found to increase with CFA proportionally. The fiber derived from $45 \%$ CFA exhibited the best tensile strength (higher than the E glass fiber prepared/tested under the same conditions) and good chemical stability (98\% mass retention in the acid corrosion test). Our study shows a feasibility of making continuous CFA derived glass fibers with high iron oxide content and an alternative way for CFA recycling. Its improved strength and good chemical durability can benefit both economy and environmental protection.
\end{abstract}

Keywords: Continuous glass fiber, fly ash, tensile strength, chemical stability, recycling.

\section{Introduction}

Research on the utilization of coal fly ash (CFA) [1] has been carried out for several decades, which led to the development of several commercially viable recycling 
methods [2], including glass-ceramics [3], glass foams [4], geopolymers, etc. The coalbased energy infrastructure in China generates more than 600 million tons of CFA each year, which has motivated us searching for other alternative CAF recycling methods. Previously, a study on the production of continuous glass fiber from municipal incinerator ash and Venice lagoon sludge was reported by Scarinci et al. [5], in which a marketable fiber glass product was produced, yet the fiber product appeared to have tensile strength lower than that of the conventional E-glass fibers. A follow-up study by Hreglich et al. [6] concluded that the vitrification process guarantees the complete neutralization of hazardous industrial wastes, and reduces the raw materials for commercial glass fiber as well as lower melting energy consumption.

In 2015, our research group has successfully demonstrated recycling molten blast furnace slag into short glass fibers at an industrial scale. Recent studies on basalt fiber [7] have shown that basalt fibers can offer high tensile strength and great resistance to chemical degradation, which greatly inspire us to examine CFA recycling by making continues glass fibers with improved mechanical and chemical performance.

In this work, the continuous glass fibers were successfully prepared from the CFA. The effects of CFA contents on the properties of the glass fibers were studied.

\section{Experimental procedures}

Materials: Chemical compositions of the CFA used in this work (measured by $\mathrm{XRF}$ ) are shown in Table 1. We sieved the CFA powder by using an 80-mesh sieve to narrow the particle size distribution. In the batch preparation, $\mathrm{SiO}_{2}, \mathrm{CaCO}_{3}$, and $\mathrm{MgCO}_{3}$ were mixed with CFA according to the designed formulation, adjusting the final glass major oxide concentrations around E-glass fiber. The samples with $25 \%$ to $55 \%$ CFA contents are labeled as F25 to F55. Final compositions and properties of the glass fibers are summarized in Table 1. 
Table 1 Chemical compositions (wt \%) and properties of CFA derived fibers

\begin{tabular}{|c|c|c|c|c|c|c|c|c|}
\hline \multirow{2}{*}{ Sample } & \multirow{2}{*}{$\mathrm{SiO}_{2} \mathrm{Al}_{2} \mathrm{O}_{3} \mathrm{CaO}$} & \multirow{2}{*}{$\mathrm{Fe}_{2} \mathrm{O}_{3}$} & \multirow{2}{*}{ Others } & \multirow{2}{*}{$\begin{array}{l}\text { Glass density } \\
\qquad / \mathrm{g} \cdot \mathrm{cm}^{-3}\end{array}$} & \multirow{2}{*}{$\begin{array}{c}\text { Drawing } \\
\text { temperature } \\
\quad /{ }^{\circ} \mathrm{C}\end{array}$} & \multirow{2}{*}{$\begin{array}{l}\text { Drawing } \\
\text { flow } \\
/ \mathrm{g} \cdot \mathrm{min}^{-1}\end{array}$} & \multicolumn{2}{|c|}{$\begin{array}{c}\text { Sample mass retention } \\
\qquad / \%\end{array}$} \\
\hline & & & & & & & $\begin{array}{l}\text { Acid } \\
\text { corrosion }\end{array}$ & $\begin{array}{l}\text { Alkali } \\
\text { corrosion }\end{array}$ \\
\hline CFA & 43.4226 .7610 .99 & 6.69 & 12.14 & & & - & & \\
\hline F25 & $\begin{array}{lll}53.34 & 6.99 & 27.87\end{array}$ & 1.75 & 10.14 & $2.569 \pm 0.019$ & 1300 & $0.203 \pm 0.011$ & $91.0 \pm 1.3$ & $85.5 \pm 0.7$ \\
\hline F35 & $\begin{array}{lll}53.87 & 9.78 & 24.02\end{array}$ & 2.45 & 9.88 & $2.553 \pm 0.028$ & 1315 & $0.147 \pm 0.009$ & $94.4 \pm 0.9$ & $82.0 \pm 0.5$ \\
\hline F45 & 53.4012 .5821 .17 & 3.15 & 9.70 & $2.572 \pm 0.005$ & 1330 & $0.100 \pm 0.017$ & $98.0 \pm 0.6$ & $75.0 \pm 1.2$ \\
\hline F55 & 51.9415 .3718 .31 & 3.84 & 10.54 & & & failed & & \\
\hline
\end{tabular}

Samples preparation: Firstly, the mixed raw materials were melted in a muffle furnace for six hours at $1450{ }^{\circ} \mathrm{C}$, and then quench each glass by immersing the hot crucible in water at room temperature. Secondly, the glass cullet was re-melted in a platinum crucible at $1400{ }^{\circ} \mathrm{C}$ and subsequently drawn into fibers at $1300-1330{ }^{\circ} \mathrm{C}$, depending on the melt viscosity. Fibers were drawn at a speed of $50 \mathrm{~m} / \mathrm{s}$ to control fiber diameters around $35 \mu \mathrm{m}$. Finally, single fibers were used for mechanical and chemical tests.

It was found that the required drawing temperature increased, but mass flow decreased, as the CFA content in the glass increases. The fiber drawing process was steady without any interruption, or fiber breakage, for glasses with CFA loading from $25 \%$ to $45 \%$, which implies no glass devitrification (process of crystallization from molten glass) occurred at the fiber drawing temperatures. As CFA loading in the glass increased to $55 \%$, it was not feasible to keep fiber process steady without fiber breakage at $1345^{\circ} \mathrm{C}$. Therefore, the fiber drawing was determined.

Characterization techniques: Differential thermal analysis (DTA) was performed by using TG Q5000IR system. Glass density was measured by using Mettler Toledo Density Meter (AL104). X-ray Powder Diffractometer (D2 PHASER) was used to 
check fiber glass for crystal formation. Morphology of the samples was studied by using scanning electron microscopy (SEM, SU8010). The tensile strength of glass fiber was measured by using Single Fiber Electronic Tensile Strength Tester (5A); averaged values were reported based on five individual measurements.

Chemical durability tests: The chemical durability was assessed by leaching tests conducted in $3 \mathrm{M} \mathrm{HCl}$ and $1.5 \mathrm{M} \mathrm{NaOH}$ at $90^{\circ} \mathrm{C}$ for $24 \mathrm{~h}$.

\section{Results and discussion}

\subsection{DTA and crystalline phase analysis}

Fig.1 (a) shows DTA curve of the F35 sample, from which the glass transition temperature $\left(\mathrm{T}_{\mathrm{g}}\right)$, around $438.7^{\circ} \mathrm{C}$, was determined and the crystallization temperature $\left(\mathrm{T}_{\mathrm{x}}\right)$ is approximately $800.9{ }^{\circ} \mathrm{C}$. Drawing fibers at temperatures greater than $1300{ }^{\circ} \mathrm{C}$, crystallization in the molten glasses or in fibers existing the bushing tip, therefore, can be avoided. The XRD patterns of the samples shown in Fig.1 (b) indicates the absence of discreet crystallization peaks, implying that all of the glass fibers produced are amorphous. 
(a)

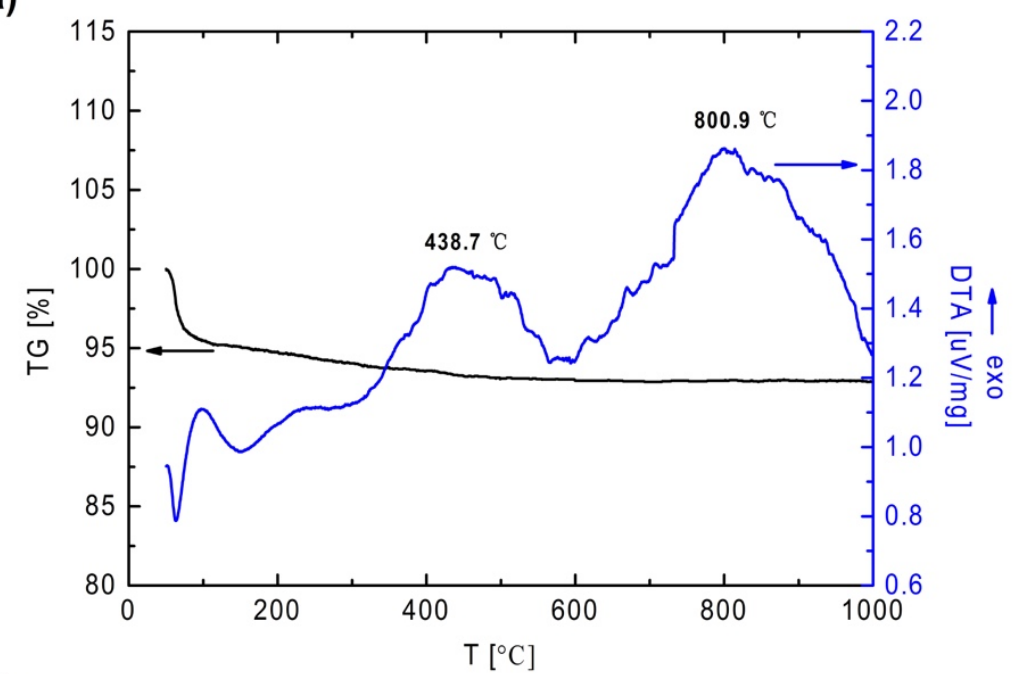

(b)

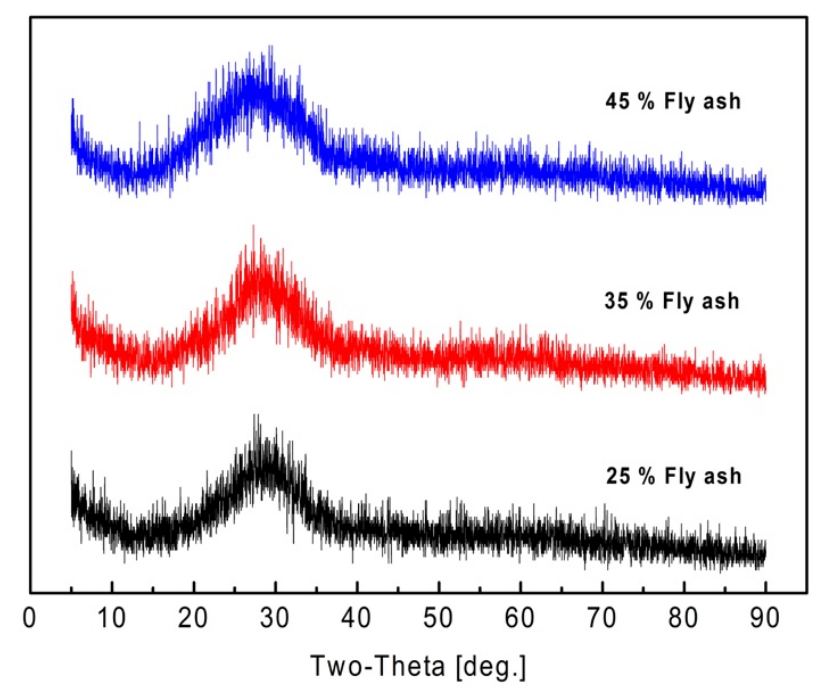

Fig.1 (a) DTA pattern of the sample with $35 \%$ fly ash content; (b) XRD pattern of samples with different fly ash content.

\subsection{Chemical stability}

Evaluations of the fiber chemical stability are summarized in Table 1. In general, the acid resistance of CFA derived fibers is better than alkali resistance of their counterparts. Previous research [8] showed that, $\mathrm{SiO}_{2}$, a primary glass network former, efficiently prevented glass fibers from the acid attack. During the process of the glass surface hydrolysis, a silicate gel was found on the fiber surfaces, which acted as a protective layer slowing down the kinetics of the acid attack. Besides, the CFA derived fibers contain little alkalis $\left(\mathrm{Na}_{2} \mathrm{O}\right.$ and $\mathrm{K}_{2} \mathrm{O}$ less than $\left.1 \%\right)$ and hence, a limited ion- 
exchange between $\mathrm{H}^{+}$and alkali ions is expected, which also benefits the fiber acid resistance.

The microstructure of the glass fibers characterized by SEM is shown in Fig.2. Compared to the pristine fiber surfaces in Fig.2 (a), the fiber surface after the acid treatment in Fig.2 (b) became slightly coarse. In alkaline solution, however, the corroded fiber surface contained a much alerted, thick layer, more than $50 \%$ fiber diameter, suggesting a severe alkaline attack on the fiber surfaces without any protection from a possible passivation layer. Comparing with Fig.2 (a) for fiber corrosion in an acid solution, fiber reaction and hence its associated damage in an alkali solution is much more severe as shown in Fig. 2(c). The observations are consistent with the fiber mass retention differences for the two corrosion cases (cf. Table 1). For the latter, the glass network structure is believed to be weakened or destroyed by strong hydrolysis of the $\mathrm{Si}-\mathrm{O}-\mathrm{Si}$ bond, $\mathrm{Si}-\mathrm{O}-\mathrm{Al}$ bonds, and/or Al-O-Al bonds by $\mathrm{OH}^{-}$groups in the solution.

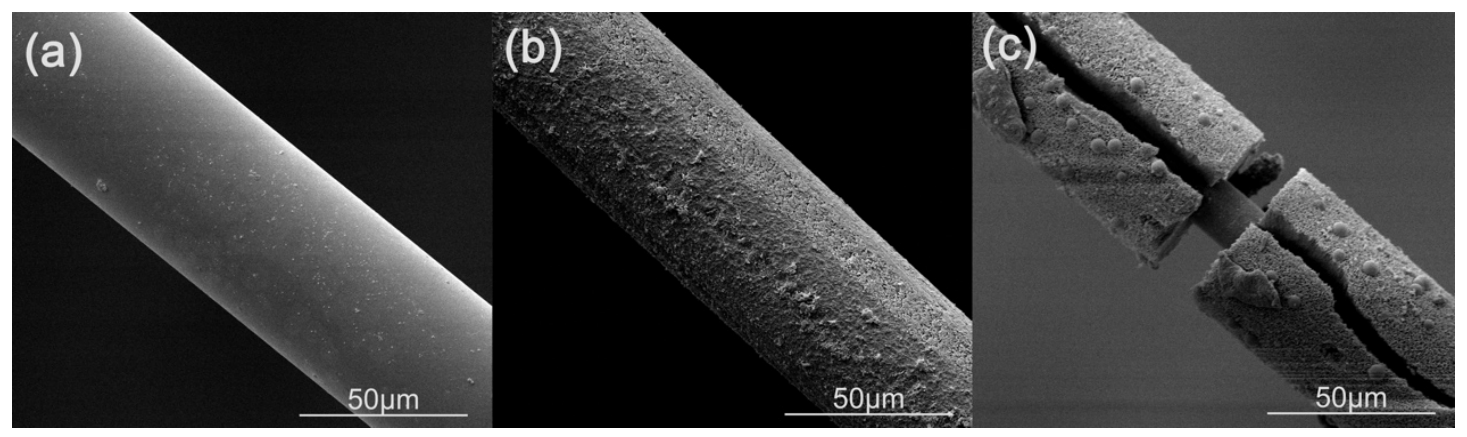

Fig.2 SEM morphology of samples with $45 \%$ fly ash content. (a) No corrosion; (b) Acid corrosion (3 mol/L HCl 24h); (c) Alkali corrosion (3 mol/L NaOH 24h).

\subsection{Tensile strength}

The tensile strength of the fiber samples in this work was measured under the same conditions, and the results are shown in Fig.3. We note that the tensile strength measured here is relatively lower compared to the reference data of commercial E glass fibers [9]. It is known that fiber tensile strength can be affected by many factors such as sample gage length, measurement temperature, and moisture, fiber diameter, the 
degree of fiber aging and atmosphere, etc. [10]. Indeed, the mechanical properties of reinforced E glass fiber and fly ash fiber reported by Hreglich et al., [6] were similarly with $\sim 300 \mathrm{MPa}$. In this work, the fiber tensile strength increases with the increase in CFA content from $\sim 320 \mathrm{MPa}$ at $25 \%$ to $\sim 420 \mathrm{MPa}$ at $45 \%$, which is equivalent or slightly higher than E glass fiber samples (tensile strength ranging from 320-350 MPa), which were prepared using the same procedure.

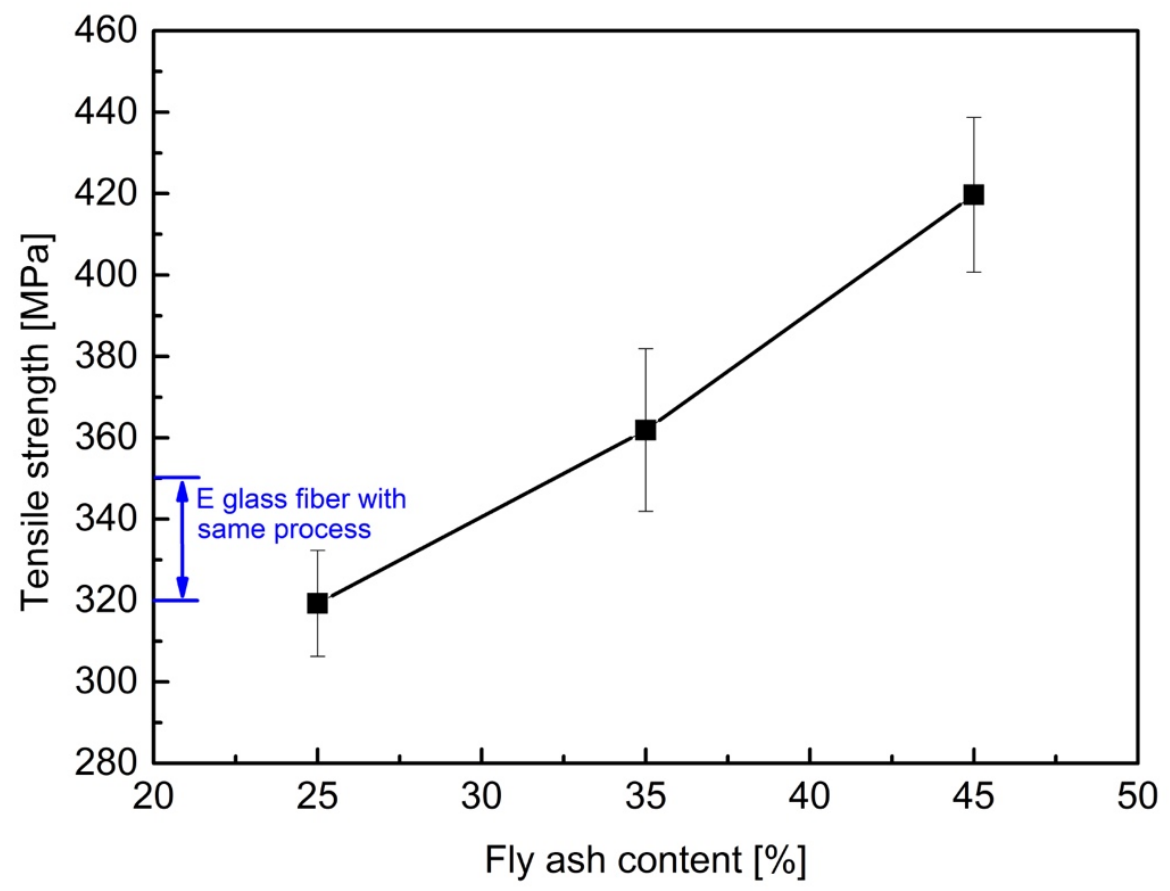

Fig.3 Tensile strength of samples with different fly ash content. Testing parameters: $20 \mathrm{~mm}$ length, $25{ }^{\circ} \mathrm{C}, 80 \%$ relative humidity, aging for 180 minutes in air conditions.

High $\mathrm{Al}_{2} \mathrm{O}_{3}$ content in the CFA derived fibers was shown to increase fiber tensile strength, which can be attributed to its strengthening mechanism of the glass network according to literature. In our case, it is also plausible that $\mathrm{Fe}_{2} \mathrm{O}_{3}$, though acting as a glass network modifier [11], might also benefit the fiber tensile strength because of its influence on slowing down fiber surface hydrolysis.

\section{Conclusions}


In this work, continuous glass fibers with different CFA content were prepared. The tensile strength of the samples increases with increasing of CFA content. The sample with $45 \%$ CFA exhibited the best tensile strength ( 420 MPa) higher than E glass fiber prepared by using the same process. The fibers also show good chemical durability ( $>91 \%$ mass retention after acid corrosion). Our results suggest a feasibility of producing CFA derived glass fibers as one of CFA recycling methods; the fibers can be commercially viable for lower costs and sufficient mechanical strength.

\section{Acknowledgment}

This work is supported by the Fundamental Research Funds for the Central Universities and the Chinese Ministry of Science and Technology. (Grant No.2013G111009). Linfeng Ding is funding by the European Union's Horizon 2020 research and innovation program under the Marie Sklodowska-Curie grant agreement No. 642029.

\section{References}

[1] A.R. Boccaccini, M. Bücker, J. Bossert, K. Marszalek, Glass matrix composites from coal flyash and waste glass, Waste Manage 17(1) (1997) 39-45.

[2] P. Colombo, G. Brusatin, E. Bernardo, G. Scarinci, Inertization and reuse of waste materials by vitrification and fabrication of glass-based products, Curr Opin Solid St M 7(3) (2003) 225-239.

[3] I. Ponsot, E. Bernardo, E. Bontempi, L. Depero, R. Detsch, R.K. Chinnam, A.R. Boccaccini, Recycling of pre-stabilized municipal waste incinerator fly ash and soda-lime glass into sintered glass-ceramics, J Clean Prod 89 (2015) 224-230.

[4] B. Chen, Z.W. Luo, A.X. Lu, Preparation of sintered foam glass with high fly ash content, Mater Lett 65(23-24) (2011) 3555-3558.

[5] G. Scarinci, G. Brusatin, L. Barbieri, A. Corradi, I. Lancellotti, P. Colombo, S. Hreglich, R. Dall'Igna, Vitrification of industrial and natural wastes with production of glass fibres, J Eur Ceram Soc 20(14-15) (2000) 2485-2490.

[6] S. Hreglich, F. Cioffi, Continuous glass fibres from waste and their application in reinforced materials, Adv Appl Ceram 108(1) (2009) 22-26.

[7] K.L. Kuzmin, S.I. Gutnikov, E.S. Zhukovskaya, B.I. Lazoryak, Basaltic glass fibers with advanced mechanical properties, Journal of Non-Crystalline Solids 476 (2017) 144-150.

[8] B. Wei, H. Cao, S. Song, Tensile behavior contrast of basalt and glass fibers after chemical treatment, Materials \& Design 31(9) (2010) 4244-4250. 
[9] H. Li, T. Charpentier, J.C. Du, S. Vennam, Composite reinforcement: Recent development of continuous glass fibers, Int J Appl Glass Sci 8(1) (2017) 23-36.

[10] Q.W. Wang, R.K. Brow, H. Li, E.A. Ronchetto, Effects of ageing conditions on E-glass failure strain and dynamic fatigue, Glass Technol-Part A 57(2) (2016) 58-61.

[11] V. Simon, S. Simon, Structural investigations on calcium-silica-phosphate glasses, Modern Physics Letters B 16(20) (2002) 761-767. 